\title{
Floridi/Flusser: Parallel Lives in Hyper/Posthistory
}

\author{
Vassilis Galanos \\ Royal School of Library and Information Science, University of Copenhagen \\ onesecbeforetheend@gmail.com
}

\begin{abstract}
Vilém Flusser, philosopher of communication, and Luciano Floridi, philosopher of information have been engaged with common subjects, extracting surprisingly similar conclusions in distant ages, affecting distant audiences. Curiously, despite the common characteristics, their works have almost never been used together. This paper presents Flusser's concepts of functionaries, informational environment, information recycle, and posthistory as mellontological hypotheses verified in Floridi's recently proposed realistic neologisms of inforgs, infosphere, e-nvironmentalism, and hyperhistory. Following Plutarch's literature model of "parallel lives," the description of an earlier and a more recent persona's common virtues, I juxtapose the works of the two authors. Through that, their "virtues" are mutually verified and proven diachronic. I also hold that because of his philosophical approaches to information-oriented subjects, Flusser deserves a place in the history of Philosophy of Information, and subsequently, that building an interdisciplinary bridge between philosophies of Information and Communication would be fruitful for the further development of both fields.
\end{abstract}

\section{Introduction}

It is probably true quite generally that in the history of human thinking the most fruitful developments frequently take place at those points where two different lines of thought meet. These lines may have their roots in quite different parts of human culture, in different times or different cultural environments or different religious traditions: hence if they actually meet, that is, if they are at least so much related to each other that a real interaction can take place, then one may hope that new and interesting developments may follow. (Heisenberg, 2000, p. 129)

Communication can be conceived as the exchange of information and information can be conceived as the main source of communication. Information and Communication Technologies (ICT's) are the technologies that bring the two concepts technically theoretically and practically - near to each other. Vilém Flusser (1920-1991) and Luciano Floridi (1964-) are two figures that have brought them near philosophically. The former has mostly been associated to fields of media theory and has been described as a "philosopher of communication" (Finger et al, 2011, p. xviii). The latter is known for his work on the philosophy of technology and computing and has coined the term "Philosophy of Information" (PI, Floridi, 2011, p. 13-17). Both authors have written about history, more 
specifically on its transcendence. One names it posthistory, one calls it hyperhistory ${ }^{1}$. Both attribute this transcendence to ICT's development.

Greek/Roman historian Plutarch wrote a series of books under the general title "Parallel Lives." Each of them contains a pair of biographies of a Roman and an earlier Greek persona of historical importance, emphasizing on their common virtues (Duff, 1999, p. 2-3). Here, I borrow this scheme of analogy, drawing parallels on common "virtues" between the aforementioned philosophers. Paraphrasing the entry for "Parallel Lives" in the MerriamWebster's Encyclopedia of Literature (1995), by comparing Flusser and Floridi, I intend to emphasize on the patterns of behavior, commonly traced in the works of the two, and to encourage a fruitful dialogue between the philosophy of communication and the PI.

Floridi recognizes the origins of PI in the works of several authors, even the ones that escape the philosophical theories of information and communication sciences. As he notices, "it is perfectly legitimate to speak of PI even in authors who lived centuries before the information revolution. It will be fruitful to develop a historical approach and trace PI's diachronic evolution" (Floridi, 2011, p. 15). I hold that Flusser stands as a unique recent exemplar for PI's diachronicity, as his work pinpoints to topics-of-the-day for the field, despite his accidental exception from the field's literature. Hence, this paper may be considered a paradox: a historical approach to the works of two authors defending history's abandonment, as a solid defense of a non-historical standpoint. Yet, the paradox is solved easily: History is not excluded from post- or hyperhistory - only the opposite is valid. Being hyper- or posthistorically permits the usage of historical, even prehistorical elements. More than a vertical continuity in PI's continuity in time, this paper aims showing a horizontal continuity of PI in disciplines towards communication and media studies, where Flusser is mostly studied. Flusser's engagement with PI topics before PI's emergence functions as an extra verification for PI's realism. PI topics as expressed through Floridi belong to the sphere of a realistic approach to information. The same subjects expressed through Flusser belong to the sphere of a hypothetical view to the future of communication. Now, that the two meet. this paper is addressed to information and communication researchers aiming at a unified (hyper/post)historical point of view towards current open problems in PI and communication and media studies.

\subsection{Methodology - Background - Scope}

The main analysis is divided into five chapters based on the common themes found in the two authors' oeuvre. Chapter 2 sets the basic moral shift of the opposition "good vs evil" to "information vs entropy" within informational environments that call for IE. Chapter 3 is describes the ontology of this environments' moral agents, called functionaries/inforgs. Chapter 4 describes hyper- and posthistory, and their impact on time and space perception, as well as the differentiation between hyper/posthistorical and historical societies. Chapter 5 explores what information oriented ecological modes of behavior the two authors suggest.

1 See Vlieghe (2013) for a remark on the similarity between Flusser and Floridi's "hyper/post-histories. 
Finally Chapter 6 presents their commonality of themes when treating the ludic mode of behavior, and also their disagreement in its interpretation.

In respect to historical sequence, Flusser has been prioritized to Floridi. The reader is encouraged to read a fictitious "discussion" between the authors where Floridi provides with fresh replies to Flusser's prophetic theses. The "parallel lives" paradigm aims at leaving a taste of unification to the reader. Drawing parallels is the base for starting a dialogue, as when proposing "friendships" in social networks based on common interests after a common pattern recognition. I am not scholastically introducing or comparing the two authors' oeuvre. I emphasize on their commonalities to open a path that I believe should be opened a long time ago. Strictly speaking: to my knowledge the two philosophies never overlapped in the literature, only surrounding aspects of them in terms of theory or reference. That's why I don't include any previous work on the topic. The aim is to philosophize fruitfully using seeds from two distant, but - as I aim showing - complementary disciplines.

\section{Information contra Entropy}

The dialogue between Flusser and Floridi begins by setting the fundamental values constituting their philosophies' ethical horizons: information and entropy. Flusser usually first approaches "information" etymologically and then emphasizes on the meaning-giving aspect of information as a gesture of "culture" opposing "nature." Flusser is aware of the many different theories information has been approached with and begins one of his essays provocatively based on that fact:

Although to inform originally meant to 'dig forms into something,' it has taken on a whole series of additional meanings in the present (and, in this way, it has become a term that people use to torment one another). Still, all these meanings have a common denominator: 'the more improbable, the more informative.'

Information is the mirror image of entropy, the reverse of the tendency of all objects (the objective world as a whole) to decay into more and more probable situations and finally into a formless, extremely probable situation. (Flusser, 1987, p. 12)

Perfect communication is for Flusser the ideal information transmission (a discourse), that generates the novel information generation (a dialogue) (1983b p. 52-53). To accumulate and produce information becomes the purpose of life. "Human communication is an artistic technique whose intention it is to make us forget the brutal meaninglessness of a life condemned to death" (2002, p. 4). Any sort of biological decay is perceived as an inescapable aspect of entropy. Any sort of meaning-giving is an aspect of life, an instance of information, that humans understand as human. Yet, information is there in nature, and humans perceive it in terms of biological structures, as the :tendency toward ever more complex forms, toward an accumulation of information - as a process that leads to more improbable structures" (Flusser, 2002, p. 5-6). 
It all returns to information structures that oscillate between high and low probability, entropy/negentropy and degrees of informativeness. And since information processes are not apparent only in human functions, then the environment can be explained in terms of information. Flusser saw the turn from hard things to soft "ware" as an environmental shift: "The environment is becoming ever, softer, more nebulous, more ghostly, and to find one's way around it one has to take this spectral nature as a starting point" (Flusser, 1999, p. 87).

Turning to Floridi, his deep knowledge of discussions on information lead him to present a unified General Definition of Information (GDI) echoing the semantic approach that perceives information as the addition of meaning to the raw material of data:

GDI $\sigma$ (an infon) is an instance of semantic information if and only if:

GDI.1 $\sigma$ consists of $\mathrm{n}$ data $(\mathrm{d})$, for $\mathrm{n} \geq 1$;

GDI.2 the data are well-formed (wfd);

GDI.3 the wfd are meaningful $(\operatorname{mwfd}=\delta)($ Floridi, 2011, p. 84$)$

Floridi and Flusser follow parallel paths. To produce information is to add meaning to data and in order to do that, the data have to be well-formed, that is of more complex structures. The degrees of form of structures recognized in nature beyond biosphere, animate or inanimate, make the preservation of information a prerequisite for the preservation of life. Thus, Floridi suggests the intelligent entities' ontological migration into the "Infosphere," his neologism that "denotes the whole informational environment constituted by all informational entities (thus including informational agents as well), their properties, interactions, processes, and mutual relations" (Floridi, 2007, p. 59). "Being” becomes equal with "carrying information" as the latter is defined above. His IE is based on the ethical division between (1) existence, that is carrying information, being a "being," and (2) nonexistence, that is entropy, "absence or negation of any information", being a "non-being." By entropy he defines the indication of information degradation "leading to the absence of form, pattern, differentiation or content in the infosphere" (Floridi, 1999, p. 44). Information and entropy are straightforwardly opposed to each other by Floridi's four basic norms for IE where within the infosphere "information entropy ought not to be caused," "ought to be prevented," and "ought to be removed" (Floridi, 1999, p. 47).

Flusser treats nature as processes of information, and foresees a "softer" informational environment. Floridi treats the recognition of information processes as the new "nature," proposing the "infosphere." The struggle against entropy in such an environment renders their paths parallel. In addition to that, Flusser had his very own interpretation of thermodynamical entropy, that meant practically the natural degradation of information clearly distinguishing his unique view from physical or Shannonian entropy, just like Floridi does when defending his metaphysical entropy, or non-beingness as an opposition to Being (2008b, p. 44-45). 


\section{Functionaries/Inforgs}

The aforementioned informational organisms are in Floridian terms called "inforgs." This chapter draws the parallel between these creatures and the Flusserian notion of "functionary." Both terms imply the symmetrization process between humans and computers/robots. For Flusser, an abstract notion of the "factory" produces new forms of tools for humans, thus reshaping the very human being in return in a McLuhanesque sense of human/tools reflection: "Factories are places in which new kinds of human beings are always being produced: first the hand-man, then the tool-man, then the machine-man, and finally the robotman. To repeat: This is the history of humankind" (Flusser, 1999, p. 44-45). Floridi holds the same argument for technology's impact on "being", when using the terms "re-engineering" and "re-ontologizing": "Now, ICTs are not augmenting or empowering in the sense just explained. They are reontologizing devices because they engineer environments that the user is then enabled to enter through (possibly friendly) gateways. It is a form of initiation." (Floridi, 2007, p. 62). Flusser's "robot" could replace in certain occurrences Floridi's "ICT's" and "computers." Flusser sees the robots as evolutionary results of machines where biological and neurophysiological theories and hypotheses have been applied to them (Flusser, 1999, p. 46). As hand tools evolve into machines and machines into robots, the reflection between human and device leads to a similarity of being and a mutual dependence:

[T] he relationship between human being and robot is reversible and [...] they can only function together: the human being in effect is the function of the robot, and by the same token the robot as a function of the human being. The robot only does what the human being wants, but the human being can only want what the robot can do. A new method of manufacturing - i.e. of functioning - is coming into being: The human being is a functionary of robots that function as a function of him. This new human being, the functionary, is linked to robots by thousands of partly invisible threads: Wherever he goes, stands or lies, he carries the robots around with him (or is carried around by them), and whatever he does or suffers can be interpreted as a function of the robot (Flusser, 1999, p. 47-48)

Jumping back to Floridi, "ICTs are not merely re-engineering but actually re-ontologizing our world. [...] Human-Computer interaction is a symmetric relation" (Floridi, 2010). Describing inforgs, he explains this symmetric relation as a relation of mutual dependence. One recognizes s/he is an inforg as soon as the dependence to ICT's is obvious. In his words, placed next to Flusser's:

One day, being an inforg will be so natural that any disruption in our normal flow of information will make us sick. Even literally. [...] Today, we know that our autonomy is limited by the energy bottleneck of our batteries. [...] Google IRL (in real life) will signal the collapse of that thin membrane still separating the worlds of online and offline. [...] If you spend more time connected than sleeping, you are an inforg (Floridi, 2007, p. 63)

This smoothing process verified by the two authors can be described like this: humans and their tools are separate. The development of ICT's has made them more and more bonded, and as humans become more and more dependent on them they recognize themselves as functionaries or inforgs. The process gives space for another observation: Not only humans are dependent on ICT's, but they behave more and more like artificial intelligences, while 
artificial intelligences function more and more like humans. At a certain point functionaries and inforgs could be either humans or computers, and the differentiation holds zero ethical value. Thus, the highest value, as stressed also in the previous chapter, remains on carrying information. Flusser sees in Information Revolution a shift from industrial things to nonthings that signifies a Nietzschean revaluation of all values. In Flusser's worldplay non-things are things one cannot easily get hold of. "Non-things now flood our environment from all directions, displacing things. These non-things are called 'information' [...] All things will lose their value, and all values will be transformed into information. 'Revaluation of all values"” (Flusser, 1999, p. 86, 88). Thus the "things," animate or inanimate, carry no highest value such as "life," or "possession." The shift is a turn to the information they carry, and subsequently to their very existence: "Our existential concerns are shifting before our very eyes from things to information. We are less and less concerned with possessing things and more and more concerned with consuming information" (ibid, p. 87). These "concerns" about new "values" are confirmed through their acceptance as the basis of any ethical discourse in Floridi's IE: "From an IE perspective, the ethical discourse now comes to concern information as such, that is not just all persons, their cultivation, well-being and social interactions, not just animals, plants and their proper natural life, but also anything that exists" (Floridi, 1999, p. 43).

The main ethical discourse between information and entropy outlined in chapter 2 is sustained here as the main value attributed to the beings inhabiting the soft environment, infosphere. The ontological shift has lead humans to function more as functions of robots and ICT's, being categorized as either functionaries or inforgs. This whole process is taking place in the context of a so-called age of Information Revolution, causing a new perception in both time and space analyzed next.

\section{Information Revolution, Topology of Hyper/Post-History:}

This chapter draws the parallels between Flusser and Floridi's analyses of information revolution and their coinciding conclusions for a new perception of transcended history and geography, together with the knowledge that this perception is not common universally. Starting by information revolution, the two authors follow some different paths leading to the same "revolution." For Flusser information revolution is the most recent rung of a chain that describes humans' relation with their tools, a relation that breeds existential evolution : "As soon as a tool - e.g. a hand-axe - is introduced, one can speak of a new form of existence" (Flusser, 1999, p. 45). The first rung is the agricultural or first industrial revolution, where humans create small tools surrounding them. The second was the known industrial revolution or, for Flusser, the second industrial revolution, where huge machines are invented and placed in the center of attention with humans surrounding them (ibid, p. 45-46). "Previously the tool was the variable and the human being the constant, subsequently the human being became the variable and the machine the constant. Previously the tool functioned as a function of the human being, subsequently the human being as a function of the machine" (1983a, 23-24). Flusser then pictures how the future humans, functionaries of information revolution, or the 
third industrial revolution, will cope with their new tools "equipped with tiny or even invisible robots will be engaged in manufacture all the time and everywhere" (Flusser, 1999, 48). Given the fact he was writing in the mid-80's, his predictions are quite precise, sounding almost prophetic: "Thanks to robots, everyone will be linked to everyone else everywhere and all the time by reversible cable, and via these cables (as well as the robots) they will turn to use everything available to be turned into something and thus turned into account" (Ibid, p. 48, emphasis added). Floridi's philosophy verifies Flusser's from his realistic point of view. What Flusser was foreseeing then has happened now, in terms of being local and global simultaneously through interrelation.

Floridi agrees with Flusser on the axiom that "science" or "tools" in Flusserian terminology does not affect only humanity's epistemological standpoint, but also the ontological, or in his words "two fundamental ways of changing our understanding. One may be called extrovert, or about the world, and the other introvert, or about ourselves" (Floridi, 2009, p. 9). The "revolutionary" path he follows is different from Flusser's as he considers information revolution as the Fourth Revolution, in the sequence of another three groundbreaking scientific advancements that have shifted our ontological position in the universe. These three have verified that "we are not immobile, at the centre of the universe (Copernican revolution), we are not unnaturally separate and diverse from the rest of the animal kingdom (Darwinian revolution), and we are very far from being Cartesian minds entirely transparent to ourselves (Freudian revolution)" (ibid, p. 10). This shift of transparency leads to a fourth shift, described in the previous chapters, the shift to information environment, the infosphere, and the humans new positioning in regards to ICT's. The appearance of inforgs signifies the Floridian informational Fourth Revolution that in other cases coincides with the Flusserian sequence of agricultural and industrial ones, not only in terminology but also in its dramatic impact on locality, synchronicity, and interactions in social structures and architectural environments: "As a consequence of such reontologization of our ordinary environment, we shall be living in an infosphere that will become increasingly synchronized (time), delocalized (space), and correlated (interactions) '” (Floridi, 2007, p. 8, emphasis added, cf with previous emphasis).

For both authors this dramatic change has an impact on the perception of historical processes. In fact, both agree that "history" as a term should be abandoned and replaced by one that signifies its transcendence. In Flusserian, the proper term is "posthistory." History functioned as a one-dimensional line of events succeeding one another by the laws of cause and effect. Computational logic breaks this line, leading to "a new, dimensionless level, one to be called, for lack of a more positive designation, 'posthistory.' The rules that once sorted the universe into processes, concepts into judgments, are dissolving. The universe is disintegrating into quanta, judgments into bits of information" (Flusser, 1985, p. 15). Information revolution signifies for Flusser a passage from the material values to the immaterial ones, due to the very nature of information. These immaterial forms are getting things delocalized, leading to a negation of geographical space in favor of topological place (in Greek: topos), and a rethinking of values. He proposes that posthistory does not only give an end to history but also geography: 
Strangely, a rethinking in terms of topology rather than geography will not make the city to be designed "utopic." It is "utopic" (placeless) as long as we continue to think geographically, because it cannot be localized within a geographical place. But, as soon as we are able to think topologically - that is, in terms of networked concrete relationships - the city to be designed allows not only localization, but also localization everywhere in the network." (Flusser, 2002, p.

Thus, the "forthcoming" form of the city seems utopic, but a topological rethinking will help grounding "topics" of interests, places. Flusser's u-topic nature of posthistory includes a political comment as well, since politics in the usual sense are to be abandoned in the new topological treatment of the city (Greek: polis, that gives origin to politics). Floridi holds the similar views for the ICT's impact on politics when stating that "ICTs fluidify the topology of politics. ICTs do not merely enable but actually promote the agile, temporary and timely aggregation, disaggregation and re-aggregation of distributed groups around shared interests across old, rigid boundaries, represented by social classes, political parties, ethnicity, language barriers, and so forth." (Floridi, 2013b, p. 6). Like a straight reply to Flusser's criticism on "u-topic," he rather prefers "atopic" as an adjective to the environment of infosphere: "The infosphere, often equated to its most prominent, digital region, namely cyberspace, is not a geographical, political, social, or linguistic space. It is the atopic space of mental life, from education to science, from cultural expressions to communication, from trade to recreation" (2002a, p. 2). Floridi uses the term "hyperhistory" to describe the modus vivendi of inforgs in societies vitally dependent on ICT's. The passage below is a thorough explanation of what makes hyperhistorical societies:

Prehistory and history work like adverbs: they tell us how people live, not when or where. From this perspective, human societies currently stretch across three ages, as ways of living. According to reports [...] there are still some societies that live prehistorically, without ICTs or at least without recorded documents. [...] The greatest majority of people today still live historically, in societies that rely on ICTs to record and transmit data of all kinds. In such historical societies, ICTs have not yet overtaken other technologies, especially energy-related ones, in terms of their vital importance. Then, there are some people around the world who are already living hyperhistorically, in societies or environments where ICTs and their data processing capabilities are the necessary condition for the maintenance and any further development of societal welfare, personal well-being, as well as intellectual flourishing. (Floridi, 2012b, p. 129-130)

Floridi not only claims that a hyperhistorical way of living already takes place, but also indicates a global dysrhythmia in what historical model different societies use. The different degrees of historical perception are noted also by Flusser, that, for his time, uses the industrial paradigm as a constant for separating the societies. For Flusser the posthistory is signified by a "linguistic" shift, where historical linear codes are replaced by digital computer codes. Still, as marked earlier by Floridi, places in the world keep going "prehistorically," are "illiterate" and non-industrialized:

The transition from the industrial society to the post-industrial is being processed in the socalled 'developed' world. Simultaneously, the largest part of humanity is undergoing several progressive phases of industrialization. In the 'First World,' linear, historical thought, which is 
founded on texts, is being challenged by a thinking that is structured by post-textual codes, by technical images. In the 'Third World,' efforts are being made to increase adult literacy. (Flusser, 1983b, p. 159)

The following excerpts appear as a fictitious dialogue between the two regarding the generation gap between contemporary people and the next generations:

Flusser: "We are closer to a worker or citizen of the time of the French Revolution than to our children - yes, those children playing with electronic gadgets. Of course, this parallel may not make the current revolution any less unsettling, but it may help us to get a hold on things" (1999, p. 88)

Floridi: "In fifty years, our grandchildren may look at us as the last of the historical, Staterun generations, not so differently from the way we look at the Amazonian tribes, as the last of the prehistorical, stateless societies. It may take a long while before we shall come to understand in full such transformations, but it is time to start working on it." (2012b, p. 131)

Summing up this chapter's parallel lines: Information revolution can be perceived as the sequential result of two chains that end in the same rung: agricultural and industrial revolutions as well as the Copernican, Darwinian, Freudian ones all end up to what is recognized as information revolution, that is the technological revolution of ICT's that has affected not only our scientific and epistemological knowledge, but also our ontological and existential position and standpoint. Our position is founded in an immaterial, mental environment of information, the infosphere, that is atopic/utopian, non-political in the historical sense of the word, delocalized and synchronized. The networked delocalization and synchronization causes a new perception of transcended history, hyper/posthistory. Still, this perception is only available to societies that are completely dependent on the usage of ICT's. Several other places on Earth live still under the rules of history, and even prehistory. Both Flusser and Floridi verify that future generations will perceive us - their historical ancestors as we perceive our prehistorical ones.

\section{Nature/Culture - e-nvironmentalism.}

Another point of agreement between the two authors is the call for an ecological standpoint when it comes to information processes. Since they both suggest the acceptance of an information environment as the current main environment, it's quite probable that the development of an ecological consciousness would appear in their texts. As shown in chapter 2 , they both base their ethical philosophy on the opposition between information and entropy. Information forms the Being, generating structures, relations, and meaning. Entropy destroys the Being naturally, it's a form of a natural cycle apparent to all objects when examined under the information scope. Flusser's worldview on history consists of the humans' struggle for taming nature, a process called culture. To him, culture means to add meaning to the meaningless nature, to impose information onto it. The more informational "culture" remains, the less entropic "nature." 
$[\mathrm{M}]$ an produces, stores, and transmits new information. He increases the sum of available information. That is what history is. This contradicts the second principle of thermodynamics, which affirms the progressive decrease of the sum of all information within a closed system (the world). History, as a dam for new information is antinatural. (Flusser, 1983b, p. 51-52)

Yet, stored redundant information can be harmful. Flusser developed the following prediction based on his time's ecology issues. While in the historical, industrial times the cycle of information generation/degradation was halted at "waste" (like plastic bottles), in posthistory, the process is halted into culture, causing the - then - new problem of information flood. Flusser outlines the problem and already proposes a general philosophical and educational model of forgetting as a necessary supplement to the one of learning:

It will, on the other hand, present another, equally threatening problem. For if the circular pattern nature-culture-waste-nature begins to stall at culture rather than at waste, we will require a vast store for culture to provide storage for the flood of incoming information. Otherwise we will suffocate from a surfeit of information rather than of waste. It is already possible to see, in rough outline, what such a cultural reconstruction would look like. First, increasingly efficient artificial memories will be integrated into the culture. Second, the concept of "forgetting" will have to acquire a new and fully adjustable meaning. Forgetting must achieve equal status with learning and be recognized as equally critical to information strategy. (Flusser, 1985, p. 109-110)

Again he meets his match and prophecy fulfillment in Floridi's in-depth analysis. Living hyperhistorically invites among others "a new philosophy of nature" and "a synthetic environmentalism as a bridge between us and the world" (Floridi, 2012b, p. 130-131). While Flusser sees "nature" and "culture" as a nodes of the information cycle, Floridi proposes the marriage of "physis and techne" (Greek for nature and technique/art, 2010, p. 119) through their very dissolving process naturally/culturally accepted in the proposed mode of behavior for inforgs: "information is both the raw material we produce and manipulate and the finished good we consume." In this sense "hyperhistorical society is a neo-manufacturing society" (Floridi, 2013a, p. 250). Apart from the environmental basics that have been discussed in earlier chapters, Floridi also rings the same bell with Flusser in regards to the information overload, nowadays rediscovered as "Big Data." He first announces the effects of the problem in numbers: "It is estimated that humanity accumulated $180 \mathrm{~EB}$ of data between the invention of writing and 2006. Between 2006 and 2011, the total grew ten times and reached 1,600 EB" (Floridi, 2012a, p. 435). He then names the problem: "We have shifted from the problem of what to save to the problem of what to erase. Something must be deleted or never be recorded. Think of your smart phone becoming too full because you took too many pictures, and make it a global problem. The infosphere run out of memory space to dump its data years ago" (ibid, p. 437). Finally he directs towards the conceptualization of an info-ecofriendly mindset as a solution to the problem: We should "know which data may be useful and relevant, and hence worth collecting and curating, in order to exploit their valuable patterns. We need more and better techniques and technologies to see the small data patterns, but we need more and better epistemology to sift the valuable ones" (ibid p. 437). His ecological approach on information has also lead him to the development of the internal RPT 
model, where moral agents and informational objects are treated equally in the environment where information can be found as a resource, as a product, and as a target (RPT). Moral agents come with the duty to "consider the whole information-cycle (including creation, elaboration, distribution, storage, protection, usage and possible destruction)" for a sustainable environment (2006, p. 4-10).

Mixing Flusser and Floridi's ecological suggestions, one extracts that natural, meaningless data are transformed into cultural meaningful information. As long as there is no time to process either automatically produced data or information, a new form of waste is apparent in the infosphere, analogous to the pollution in the biosphere. The new mentality invoked by the two authors includes a know-how that accepts both generation and destruction, and calls for an ecological education based not only in production and consumption but also deletion.

\section{Game Theory - Interpretations of Homo Ludens:}

Here comes the final parallel line, a point of simultaneous agreement and disagreement. Flusser and Floridi have their last meeting point when game-theoretic terms are preferred to explain information processes and relations within informational environments. Yet, in their dialogue they disagree on the usage of Johan Huizinga's (1955) term "Homo Ludens," the playing human.

Flusser proposes that the forthcoming society's prevailing "theory" "will very probably be a game strategy. We already have a whole series of disciplines that are 'theories' in this new meaning of the term: informatics, cybernetics and decision theory to mention only a few examples" (Flusser, 1983b, p. 34). Flusser treats "gaming" and "playing" like synonyms. Then, if computers are games, played with keyboards, and game-theoretic terms describe them, fictitious games become the concrete reality, with no "reality" behind them. This mode of playing behavior is represented by the Homo Ludens, where play is made purely for play, not for a one-side victory. Winning games in posthistory does not represent earning benefits such as in the phrase "war games." Some excerpts from Flusser's game-theoretic approach to play:

The symbolic games of which we take part do not represent any universe of concrete experience, but on the contrary, this concrete experience represents games. We live our concrete experience in function of games. Games are our ontological ground and all future ontology is necessarily game theory. (Flusser, 1983b, p. 105-106)

Elsewhere, he even claims that "we are programmed to be Homines ludentes," and he puts his own explanation of "functionaries" under criticism, claiming that this playful spirit will help overcoming complete robotization and objectification, as we "may, equally, be players that play in function of the Other" (1983b, p. 166).

In my fictitiously set-up dialogue of the two authors Floridi now disrupts Flusser, holding that the ludic, playful behavior in the infosphere might be ecologically harmful. For Floridi, moral agents should be demiurgic prosumers that respect the environment. They hold responsibility 
for all three aspects of the RPT model, and thus the ludic Homo Ludens model should be abandoned due to its lack of awareness as long as play is just for play. He then proposes another term for this new inforgian human species:

Homo poieticus is to be distinguished from homo faber, user and "exploitator" of natural resources, from homo oeconomicus, producer, distributor, and consumer of wealth, and from homo ludens (Huizinga [1970]), who embodies a leisurely playfulness devoid of the ethical care and responsibility characterising the constructionist attitude. Homo poieticus is a demiurge who takes care of reality to protect it and make it flourish. $\left(2006^{2}\right.$, p. 23)

Other than that, he considers game-theoretic approaches to Computer Ethics appropriate (1999, p. 41) and for "the sake of simplicity, and following current trends" presents economic information "framed in game-theoretic terms" in even greater detail than Flusser, when introducing shortly "complete," "asymmetric," "perfect," and "Bayesian" information (2010). All these forms of game-theoretic approaches to information, though share nothing with Homo Ludens.

Here the main opposition is found - nonetheless justified by the generation gap between the authors. As said above, Flusser's philosophy of posthistorical ludic behavior is hypothetical, a sort of mellontological prognostics - with a sense of optimism. Floridi proposes that the playful mindset of Homo Ludens tested within a game-theoretic framework is incompatible with a clear ethical and ecological viewpoint in the information environment. Rightfully, it should be replaced by his Homo Poieticus, a behavior model that includes the previously mentioned "know-how" of the demiurge, with respect to the environment, causing no entropic harm to the infosphere. Still, no matter their difference, their common engagement with both Huizinga's and the game-theoretic terms adds to the exploration of the authors' common "virtues."

\section{Conclusions}

Posthistorians, people who tell a story about the end of history, are necessarily storytellers. When they tell a story about the end of history, they make history. It seems as if they are caught up in a sophistic paradox, like someone who speaks about the end of philosophy and then, with this philosophical pronouncement, drives philosophy forward. (Flusser, 2002, p. 143-144)

Flusser and Floridi now can function as complementary manifestations of a tested hypothesis, which has been proven correct to most of its consisting parts. To certain extents, Floridi's proposals seem like replies to Flusser's questions. To other extents they seem like perfect matches, or developed versions. Flusser's terms describe a forthcoming form of existence $a$ priori. It's a hypothetical view of the future world partially realized at his time. Floridi's terms describe a worldview of a realized form of existence $a$ posteriori. It's a realistic view of the current world. Summing up, Flusser's playful posthistorical functionaries function as a

2 See also Floridi's $(1999,40-41)$ treatment of hackers as an example of ludic behavior causing damage in the infosphere. 
preview of Floridi's hyperhistorical inforgs. The two notions bare same elements. New technologies ("ICT's," "robots," "computers") mark the information revolution, giving space to these new modes of existence, with ontological and existential impacts. What is now perceived as nature/environment is sustained through the ethical rules of the information game. Flusser was only descriptive about this informational environment. Floridi thoroughly analyzes its elements, and names it infosphere. Both ring the bell for an ecological approach to the information cycle. Flusser foresaw the problem. Floridi brings the evidence. From these parallels drawn here, both authors' works are benefitted. Flusser gets his theories tested and verified by current observations. Floridi's proposed terminology discovers a hyper/posthistorical ancestor.

Hence, Flusser deserves a place in the PI pantheon, and this paper proposes the study of his work with emphasis on information-theoretical terms as a vital tool for future PI studies. By the same token, it's time for Floridi's neologisms to be considered eventually less "new," getting their rightful place in the sphere of common sense, rather than the one of "neologisms," while his analysis of ICT's should be considered within communication and media studies contexts as well.

This paper's conclusions aim also to be conceived as a networking bridge linking diverse audiences from distinct fields where the works of the two authors have occasionally been used - mostly fields of information and communication theories. An interdisciplinary discussion between these fields starting by the mingle of Flusser and Floridi's already interdisciplinary spirit, can be proven more than fruitful for the further theoretical development of those fields. Sticking to words, ICT's include both "information" and "communication." Flusser and Floridi's theoretical harmonious balance does not only imply parallels for the sake of scholasticism. It's a message of diachronicity of hyper/posthistory.

More than that. Abstracting the contents of this paper, I propose the unifying perception of two gestures, one of information and one of communication. The informative gesture generates new meaning from given communicated signals. The communicative gesture preserves the meaning acquired by informing sources. Information studies are in complementarity with communication studies, in a yin and yang relation with rhizomatic structure within the inner sub-fields. Whether philosophy is the "first science" or not, it is of key importance to bridge information and communication studies on their philosophical level, as a set ground for further potential philosophical investigations between the disciplines: Let McLuhan be in dialogue with Dretske, or de Saussure negotiate with Peirce. Let the common conclusions of Flusser and Floridi flourish as a fruit of interdisciplinarity, and let "information" and "communication" become particles of a fruitful dialectic.

In hyper/posthistory variations of the same coexist in both space and time, like a digital picture of a painting taken with a camera of yesteryear's technology and one of the same painting taken with the best available resolution of today. Parallel lives like the ones of Flusser and Floridi, imply coexisting parallel universes - and Plutarch gets quantumtheoretically refreshed, having his method verified in the words of Heisenberg quoted in the beginning of this article. 


\section{References}

Duff, T. (1999). Plutarch's Lives: exploring virtue and vice. Oxford University Press.

Finger, A. K., Guldin, R., \& Bernardo, G. (2011). Vilém Flusser: An Introduction. University of Minnesota Press.

Floridi, L. (1999). Information ethics: on the philosophical foundation of computer ethics. Ethics and information technology, 1(1), 33-52.

Floridi, L. (2002a). Information ethics: an environmental approach to the digital divide. Philosophy in the Contemporary World, 9(1), 39-45.

Floridi, L. (2002b). On Defining Library and Information Science as Applied Philosophy of Information. Social epistemology, 16(1), 37-49.

Floridi, L. (2004). LIS as Applied Philosophy of Information: A Reappraisal.

Floridi, L. (2006). Information ethics, its nature and scope. ACM SIGCAS Computers and Society, 35(2), 3-3.

Floridi, L. (2007). A look into the future impact of ICT on our lives. The information society, 23(1), 59-64.

Floridi, L. (2008a). Artificial Intelligence's new frontier: Artificial Companions and the Fourth Revolution. Metaphilosophy 39. 4/5: 652-654.

Floridi, L. (2008b). Information ethics: A reappraisal. Ethics and Information Technology, 10(2), 189-204.

Floridi, L. (2009). The Information Society and its Philosophy: Introduction to the Special Issue on "the Philosophy of Information, its Nature, and Future Developments". The Information Society, 25(3), 153-158.

Floridi, L. (2010). Information: A Very Short Introduction. Oxford: Oxford University Press.

Floridi, L. (2011). The Philosophy of Information. New York: Oxford University Press.

Floridi, L. (2012a). Big data and their epistemological challenge. Philosophy \& Technology, 1-3.

Floridi, L. (2012b). Hyperhistory and the Philosophy of Information Policies. Philosophy \& Technology, 129-131.

Floridi, L. (2013a). E-ducation and the Languages of Information. Philosophy \& Technology, 26, 247-251.

Floridi, L. (2013b). Hyperhistory and the Philosophy of Information Policies. In: The Onlife Initiative. Retrieved 04-05-2014 from

https://ec.europa.eu/digital-agenda/sites/digital-agenda/files/Contribution_Floridi.pdf

Flusser, V. (1979, 2013). Natural:Mind. Minneapolis: Univocal.

Flusser, V. (1983a, 2000). Towards a Philosophy of Photography. London: Reaktion.

Flusser, V. (1983b, 2013). Post-History. Minneapolis: Univocal.

Flusser, V. (1985, 2011). Into the Universe of Technical Images. Minneapolis: University of Minnesota Press.

Flusser, V. (1987, 2011). Does Writing Have a Future? Minneapolis: University of Minnesota Press.

Flusser, V. (1999). The Shape of Things: A Philosophy of Design. London: Reaktion. 
Flusser, V. (2002). Writings. Minneapolis: University of Minnesota Press.

Flusser, V. (2003). The freedom of the migrant: Objections to nationalism. University of Illinois Press.

Heisenberg, W. (2000). Physics and philosophy. London: Penguin.

Huizinga, Johan (1955). Homo ludens; a study of the play-element in culture. Boston: Beacon Press.

Vlieghe, J. (2013). Education in an Age of Digital Technologies. Philosophy \& Technology, 1-19. 